\title{
FOREWORD
}

\section{Special Section on Next Generation Network Management}

Several types of next generation networks have been developed to satisfy the demand from users for advanced and diversified network services. These developments include implementing networks based on a new IP-based architecture, converging of fixed and wireless networks for ubiquitous infrastructure, and merging of telecommunications and broadcasting to produce new network services. A critical issue is the efficient operation and management of these networks and services, since they are becoming larger and more complex. Thus, network management technologies are becoming increasingly important. The Technical Committee on Telecommunication Management of the IEICE Communications Society organized a special section to promote management technologies for next generation networks.

We received 34 papers in response to the call for papers for this special section. Out of these papers, one invited paper related to management of Next Generation Network, nine papers and one letter were selected by the careful and impartial review of the editorial committee.

All the members of the editorial committee (who were volunteers from the Technical Committee on Telecommunication Management of the IEICE Communications Society) would like to express their sincere appreciation to all the authors and reviewers for their contributions that made this special section such a success.

Members of the Editorial Committee:

Guest Editor: Kohei Iseda (Fujitsu Laboratories)

Guest Associate Editors: Shingo Ata (Osaka City Univ.), Kenji Ishida (Hiroshima City Univ.), Yoshiaki Kiriha (NEC), Toshio Nishiyama (NTT communications), Tadafumi Oke (NTT Comware), Kiminori Sugauchi (Hitachi), Kazuhide Takahashi (NTT DoCoMo), Hiroshi Uno (NTT), Yoichi Yamashita (NTT West)

Katsushi Iwashita, Guest Editor-in-Chief

Katsushi Iwashita (Member)

received B.S., M.S., and Ph.D. degrees in electrical engineering from Kyusyu University, Fukuoka, Japan, in 1977, 1979, and 1987, respectively. In 1979, he joined the Yokosuka Electrical Communication Laboratory, NTT, where he has been engaged in research on high-speed optical fiber transmission systems, coherent optical communication and adaptive network control and management technologies. From 2004, he has served as a professor of Kochi University of Technology. He has received the IEICE Young Engineers Award in 1985 and director of Science and Technology Agency Award. He has been the Vice chair of the IEICE Technical Committee on Telecommunication Management since 2006.

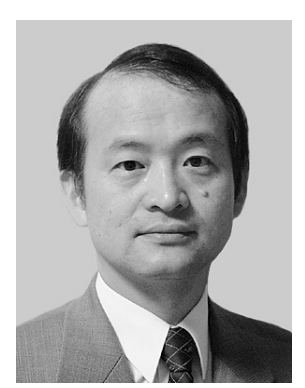

